\title{
Percepciones de diversidad sexual y discriminación a personas lesbianas, gays, bisexuales, transgeneristas e intersexuales en Corozal, Colombia
}

\author{
Trabajo de Resultado de Investigación \\ Berónica Narváez-Mercado ${ }^{17}$ \\ Carlos Andrés Galeso-Morales ${ }^{18}$
}

\section{Introducción}

Según el Alto Comisionado de las Naciones Unidas para los Refugiados, la sigla LGBTI se desglosa de la siguiente manera: la letra "L" se refiere a lesbiana, aquella mujer que es atraída física, romántica o emocionalmente de manera perdurable por otras mujeres; "G" de gay se utiliza cuando es un hombre atraído por otro hombre. A su vez puntualiza transgéneros a las personas cuya identidad de género o expresión de género difiere del sexo biológico que les fue asignado al nacer e intersexual o "trastornos del desarrollo sexual" (DSD por sus siglas en inglés) se refiere a una condición en la que un individuo nace con una anatomía reproductiva o sexual o patrones de cromosomas que no parecen ajustarse con las típicas nociones biológicas de hombre o mujer (ACNUR, 2014).

${ }^{17}$ Doctorante de la Universidad Libre de Bogotá, Colombia, Magister en Administración y Derecho Empresarial de la Universidad Libre de San José, Costa Rica. Abogada de la Universidad Libre, Bogotá, Colombia. Directora del Proyecto de Investigación de Colciencias Consuma Caribe. Directora del Centro de Investigación Socio jurídica de la Corporación Universitaria del Caribe -CECAR, sede Sincelejo, Colombia. Email: beronica.narvaez@cecar.edu.co

${ }^{18}$ Magister en Conflicto y Paz, Universidad de Medellín, Colombia, Especialista en Gobierno y Gestión Pública Territoriales, Pontificia Universidad Javeriana, Bogotá, Colombia. Defensor de DDHH y docente universitario, Director de PAZCARIBE, Sincelejo, Colombia. Email: cgaleso@gmail.com 
Las personas lesbianas, gays, bisexuales, transgeneristas e intersexuales cuentan con todas las capacidades para reclamar y ejercer sus derechos y libertades. Tales derechos por proteger son los mismos que les corresponden al resto de la sociedad, enfatizando en aquellos quebrantados por barreras de acceso a servicios e iniquidades en corolario de conductas discriminatorias, lo cual va en contra del Artículo $13^{\circ}$ Constitucional:

Todas las personas nacen libres e iguales ante la ley, recibirán la misma protección y trato de las autoridades y gozarán de los mismos derechos, libertades y oportunidades sin ninguna discriminación por razones de sexo, raza, origen nacional o familiar, lengua, religión, opinión política o filosófica (Constitución Política Colombiana, 1991, Art. 13).

La presente investigación examina datos sobre la situación de derechos humanos del sector LGBTI del municipio de Corozal, municipio colombiano del Departamento de Sucre, que hace parte de la región Caribe de Colombia y de la subregión geográfica llamada Sabanas. En el documento se presentan las actitudes y experiencias de lesbianas, gays, bisexuales, transgeneristas e intersexuales respecto a la identidad de género entendida como:

La vivencia interna e individual del género tal como cada persona la experimenta profundamente, la cual podría corresponder o no con el sexo asignado al momento del nacimiento, incluyendo la vivencia personal del cuerpo (que podría involucrar la modificación de la apariencia o la función corporal a través de técnicas médicas, quirúrgicas o de otra índole, siempre que la misma sea libremente escogida) y otras expresiones de género, incluyendo la vestimenta, el modo de hablar y los modales (Derechos Humanos, Orientación Sexual e Identidad de Género, 2012, p. 29).

Por su parte Sebastián, Málik y Sánchez (2001, p. 37) definen la categoría de género aquello que se atribuye a cada uno de los sexos en cada sociedad; aquello que, como construcción social, se considera masculino o femenino. Por consiguiente, la identidad de género se construye por los otros, debiendo el individuo integrarse en un conjunto social respetando sus normas. En definitiva, la identidad de género es una construcción social y una manera de autodefinición. En el proceso de la construcción de 
la identidad de género la sociedad suele refugiarse en los estereotipos de género (Solís, 2016, p. 100). En este mismo sentido, surge el concepto de estereotipo, el cual es un juicio que se fundamenta en ideas preconcebidas, una opinión ya hecha que se impone como como un cliché a los miembros de una comunidad. (Sebastián, et al, 2001, p. 38), lo anterior debidamente descrito en el capitulo de libro denominado la enseñanza universitaria como estrategia de construcción de paz desde una perpestiva de genero: estudio de caso de la Facultad de Derecho de CECAR (Jaimes Velásquez \& Mendoza Cortes, 2018)

A su vez, otras variables que incluyen la discriminación e integridad personal, educación, salud, empleo, cultura y recreación, participación social y vivienda. Asimismo, se detallan las impresiones de la población civil corozalera relacionada con las percepciones y valores sobre las condiciones de vulnerabilidad y segregación que afrontan las personas LGBTI. En el mismo contexto investigativo se reporta información respecto al ejercicio de la función pública frente a la diversidad sexual, la cual se define como:

La atracción física, romántica o emocional de una persona por otras personas. Todo el mundo tiene una orientación sexual, que es integral a la identidad de la persona. Los hombres gay y las mujeres lesbianas se sienten atraídos hacia personas de su mismo sexo. Las personas heterosexuales se sienten atraídas hacia personas de un sexo distinto del suyo. Las personas bisexuales (a veces simplemente "bi") se sienten atraídas hacia personas del mismo sexo o de un sexo distinto. La orientación sexual no guarda relación con la identidad de género o las características sexuales (Glosario, s.f, p.32).

$\mathrm{El}$ riesgo de que las personas LGBT e intersex "sufran torturas o tratos crueles, inhumanos o degradantes cuando se encuentran en reclusión en centros penitenciarios o en entornos policiales, administrativos, de inmigración u otros lugares de detención es motivo de especial preocupación" (Naciones Unidas, 2016, p. 37), por ende, motivó el desarrollo de un proceso de identificación voluntario, con el objetivo de determinar la situación de derechos humanos del precitado sector en el municipio de Corozal.

Cabe destacar que países como Albania, Bélgica, Chile, Honduras, el Estado Plurinacional de Bolivia, los Estados Unidos y el Reino Unido, 
han adoptado legislaciones que incluyen tanto la orientación sexual como la identidad de género en los criterios de protección y que consideran los prejuicios hacia estos motivos como un factor agravante en las sentencias penales. Treinta y nueve Estados incluyen la orientación sexual como factor agravante en sentencias penales y treinta y cuatro han promulgado leyes sobre la incitación al odio con base en la orientación sexual (Carroll, 2016).

Los principios de Yogyakrta mencionan en el Principio 13, que todas las personas tienen derecho a la seguridad social y a otras medidas de protección social, sin discriminación por motivos de orientación sexual o identidad de género y a su vez los Estados adoptarán todas las medidas legislativas, administrativas y de otra índole que sean necesarias a fin de asegurar el acceso, en igualdad de condiciones y sin discriminación por motivos de orientación sexual o identidad de género, incluyendo beneficios laborales, licencia por maternidad o paternidad, beneficios por desempleo, seguro, atención o beneficios ligados a la salud (incluso para modificaciones del cuerpo relacionadas con la identidad de género), otros seguros que cubran cuestiones sociales, beneficios familiares, beneficios funerarios, pensiones y beneficios para paliar la pérdida de apoyo como resultado de enfermedad o muerte de cónyuges o parejas. Asegurarán que no se someta a niñas y niños a ninguna forma de trato discriminatorio en el sistema de seguridad social o en la prestación de beneficios sociales o de bienestar social por su orientación sexual o identidad de género, o la de cualquier integrante de su familia y adoptarán todas las medidas legislativas, administrativas y de otra índole que sean necesarias a fin de garantizar el acceso a estrategias y programas de reducción de la pobreza, sin discriminación por motivos de orientación sexual o identidad de género. "Nadie será sometido a torturas ni a penas o tratos crueles, inhumanos o degradantes. En particular, nadie será sometido sin su libre consentimiento a experimentos médicos o científicos" (Pacto Internacional de Derechos Civiles y Políticos, 1966).

Respecto a la percepción sobre diversidad sexual en la población civil, la discriminación por orientación o preferencia sexual sigue siendo de las que más mitos, falsedades, generalizaciones y satanizaciones evoca; al mismo tiempo, es factor de unión, de jocosidad, de burla, de promoción de odio 
y de violencia socialmente justificada y hasta exaltada, que aún prevalece en nuestra cultura. Cuando ocurren delitos motivados por el odio con base en la orientación sexual, la identidad de género o los caracteres sexuales, las víctimas deben tener acceso a reparación y apoyo, incluyendo remisión a soporte legal, servicios especializados médicos, psicológicos y de otra índole y refugios y centros de acogida cuando sea necesario. La Comisión Europea ha financiado un informe que destaca las buenas prácticas de las organizaciones gubernamentales y no gubernamentales para ayudar a las víctimas de delitos para que puedan acceder a este tipo de apoyo e identifica los múltiples obstáculos a los que las víctimas LGBT de delitos se enfrentan para acceder a la justicia (Rukšènaitè, 2011).

Frente a la situación de discriminación los Estados deben garantizar que las personas LGBT e intersex dispongan de un acceso igualitario a los centros de salud, entre ellos, aquellos específicos para la salud sexual y reproductiva. Asimismo, se debe capacitar al personal sanitario para que respeten los derechos humanos de las personas LGBT e intersex, incluyendo los derechos de dignidad, privacidad, autonomía e integridad física y psicológica, y para concienciar acerca de las necesidades sanitarias de las personas LGBT e intersex en ámbitos como la salud y los derechos sexuales y reproductivos, la salud mental, la prevención del VIH y el asesoramiento sobre tratamientos y traumas. Las buenas prácticas incluyen la creación de protocolos de salud para abordar las distintas necesidades sanitarias de las personas LGBT e intersex en conformidad con las normas internacionales en materia de derechos humanos. El acceso a la salud no debe basarse en categorías de diagnósticos estigmatizantes y patologizantes (Naciones Unidas, 2016). Discriminación y homo/transfobia Tal como se menciona en los Artículos $1^{\circ}$ y $2^{\circ}$ de la Declaración Universal de Derechos Humanos los cuales establecen respectivamente que: "Todos los seres humanos nacen libres e iguales en dignidad y derechos" y que "Toda persona tiene los derechos y las libertades proclamados en esta Declaración” (Declaración Universal de Derechos Humanos, 1948).

Respecto a la educación sexual y discriminación en instituciones educativas, consideramos indiscutiblemente la discriminación a lesbianas, gays, bisexuales, transgeneristas e intersexuales en las aulas es un problema 
cotidiano que afecta la calidad de vida de estudiantes y/o docentes identificados con una orientación sexual o identidad de género diversa. Conocer ampliamente los alcances de esta realidad es fundamental para implementar acciones afirmativas que procuren el ejercicio pleno de los derechos de las personas LGBTI.

Lo anterior condujo a analizar valores, actitudes y prácticas de la población corozalera con respecto a la discriminación.

\section{Método}

El estudio antropológico se enmarca en el enfoque mixto, pues integró un proceso etnográfico como método de investigación social, por medio de la observación de campo y la indagación, cuyo instrumento utilizado fue una encuesta que desarrolla un grupo de preguntas estructuradas y semi estructuradas, lo más cercanas posibles a un significado común para todos los encuestados. El informe investigativo cuenta con la participación de cuatro (4) muestras que sumaron un total de mil setenta y siete (1.077) entrevistas a lo largo del municipio. La edad establecida para la muestra confluye en un rango de los 16 a los 40 años, de todos los estratos socioeconómicos. La primera es una entrevista institucional, con una muestra representativa de ciento siete (107) funcionarios y contratistas de la Alcaldía del Municipio de Corozal; la segunda que integra los sectores LGBTI, participaron 88 miembros de la comunidad LGBTI; la tercera a la población estudiantil, con 223 estudiantes de bachillerato en el Municipio de Corozal y finalmente, la de población civil residente en el mismo territorio. La muestra de la población civil fue establecida en seiscientos cincuenta y nueve (659) hogares, conformada por cuatrocientas siete (407) mujeres y doscientos treinta y un (231) hombres.

La distribución de las muestras corresponde al año 2017 y se presenta en términos de plausibilidad entre los encuestados y los rasgos sociodemográficos más importantes, incluyendo la identificación del género, la orientación o preferencia sexual y el sexo, edad, nivel socioeconómico, estado civil y práctica religiosa.

El grado de participación por cada muestra se fijó en más del noventa por ciento (90\%) de los intervinientes, donde la muestra de los secto- 
res LGBTI estuvo liderada por aquellas personas que se reconocen gays con un 48.86\%, seguido de los individuos que se identifican como hombres y mujeres, representado cada sexo con el $19.32 \%$ el sexo masculino y $10.23 \%$ el sexo femenino. Se infiere simetría en los participantes de la encuesta de Educación Sexual y Discriminación en Instituciones Educativas (Encuesta, 2017).

\section{Resultados}

Se logró identificar que el $51.14 \%$ de los encuestados de los sectores LGBTI se encuentra entre las edades de 25 a 39 años. De igual forma, el $48 \%$ de los funcionarios y contratistas del municipio de Corozal converge con el precitado rango de edad. Se detalla que el mayor número de entrevistados en la muestra de población civil se ubican en edades entre 18 a los 29 años. Del mismo modo, el 76.68\% de los 223 estudiantes encuestados no sobrepasan los 16 años.

Al consultar el estado civil de los indagados, se precisa un $87.50 \%$ de personas solteras frente a un $5.68 \%$ de casados en el colectivo LGTBI. La misma pregunta aplicó para los funcionarios y contratistas del Municipio de Corozal, estableciéndose que un 50\% de ellos son solteros mientras que un $44 \%$ manifestaron tener un cónyuge. La mayor proporción de matrimonios o uniones maritales de hecho se observa en la población civil con un $52.46 \%$.

En cuanto a la tenencia de hijos, el sondeo expone que nueve de cada diez personas del sector LGBTI no los tiene; pero la muestra institucional y la de población civil reflejan que seis de cada diez encuestados sí los ha concebido.

También se examinó si los corozaleros practican alguna religión y la periodicidad con que asisten a estos servicios religiosos. Se concluye que la religión católica es la más aceptable entre las muestras de los sectores LGBTI, institucional y población civil, pues cerca de ocho de diez personas así lo declararon. Con todo y eso, tres de cada diez personas LGBTI acuden a los actos religiosos con mayor frecuencia solo en días feriados $\mathrm{u}$ ocasiones especiales, mientras que el $45 \%$ de los funcionarios y contratistas del Municipio de Corozal lo hacen semanalmente. 
Para completar la descripción de las muestras, el 89.35\% de los encuestados de la muestra de población civil pertenece al nivel socioeconómico uno y dos.

En relación a la percepción sobre integridad personal, la investigación revela que el $54.55 \%$ de las personas lesbianas, gays, bisexuales, transgeneristas e intersexuales se han sentido a menudo, a veces y rara vez incómodas por su condición de género, preferencia sexual o apariencia física. De este porcentaje el 19.32\% estima que la orientación sexual es la condición primordial para sentirse incómoda. También un $23.86 \%$ de la población LGBTI revela su inconformidad cuando son observados en lugares públicos por su apariencia física.

De la misma manera, el $62.50 \%$ aclara que nunca ha sido discriminado por su círculo familiar, frente a un $37.50 \%$ que manifiesta haber padecido un comportamiento discriminatorio cometido por padres, hermanos, tíos, abuelos o parientes lejanos.

Conviene señalar que tres (3) de cada diez (10) encuestados ha sufrido alguna vez agresión física o verbal con ocasión de su condición de género, preferencia sexual o apariencia física. Añádase que cerca de seis (6) de cada diez (10) interrogados ha conocido a alguien que sufrió una muerte violenta a causa de su orientación sexual o identidad de género; sindicando a sujetos desconocidos como los principales agresores de la población LGBTI.

La percepción de seguridad de los entrevistados en cuanto a qué tan seguro se siente cuando visita un sitio público frecuentado por lesbianas, gays, bisexuales, transgeneristas e intersexuales en el municipio de Corozal reflejó que el $21.59 \%$ de los consultados se siente muy seguro; opinión coincidente con el $43.18 \%$ de personas LGBTI que considera sentirse tranquilo en lugares públicos habitualmente concurridos por este sector social. Llegado a este punto, es pertinente acotar que cerca de tres (3) de cada diez (10) encuestados ha sido víctima de atraco y dos (2) de cada diez (10) ha soportado agresiones verbales en estos espacios de esparcimiento, recreación y socialización.

De colofón, se cuestionó por la relación de los sectores LGBTI y la Policía Nacional de Colombia. El estudio permitió inquirir si los partici- 
pantes habían sido detenidos por este cuerpo de seguridad pública y qué tipo de situaciones se presentan al momento de realizarse el mencionado procedimiento policivo. Cerca del $90 \%$ de los investigados nunca ha sido detenido por la Policía; sin embargo, uno de cada diez consultados alega que al momento de realizarse su aprehensión se utilizó violencia.

Respecto a la discriminación por orientación sexual e identidad de género y las actitudes frente a la discriminación, el 67\% de lesbianas, gays, bisexuales y transgeneristas en el municipio de Corozal se ha resistido a algún tipo de discriminación; resaltando que tres de cada diez personas de los sectores LGBTI enuncian haber sido discriminados por amigos y por lo menos dos (2) de ellos paralelamente ha sido excluido de un espacio religioso, maltratado por guardas de seguridad, mal atendido por una entidad gubernamental, impedido para donar sangre y le han prohibido el ingreso a un local comercial. Cabe señalar, que frente a los anteriores actos discriminatorios, el $42 \%$ de los encuestados no contó y no pidió ayuda a nadie en su entorno familiar o personal. Solo uno de cada diez personas LGBTI decidió compartir tal circunstancia con su compañero de estudio/trabajo, madre, pareja o vecino.

Institucionalmente, la proporción fue mayor, pues el $80.68 \%$ de las personas de los sectores LGBTI afirma no haber denunciado el hecho discriminatorio en ninguna entidad del Estado. Valga aclarar que, por lo menos, uno (1) de cada diez (10) de los entrevistados acudió a organizaciones defensoras de derechos humanos para dar a conocer la eventualidad acaecida. Materia importante de analizar es la forma de actuar de los sectores LGBTI al presenciar un episodio discriminatorio. Siete (7) de diez (10) informantes observaron en el decurso de su vida algún tipo de discriminación; aunque solo seis (6) de ellos mostraron inconformidad con la situación. Al mismo tiempo, sostiene el $78.41 \%$ de los declarantes que nunca han discriminado a alguien por tener una preferencia sexual diferente a la suya.

En lo que atañe a la educación de los sectores LGBTI el 32.95\% de las personas encuestadas dicen haber sido discriminadas en la escuela, colegio o universidad. E1 78.41\% de lesbianas, gays, bisexuales, transgeneristas e intersexuales no asiste actualmente a establecimientos educativos, pese a 
que el $46.59 \%$ culminó sus estudios secundarios y tres de cada diez de los entrevistados alcanzó título de pregrado.

Debido a su orientación sexual o identidad de género el 17\% de las personas indagadas expresa haber sido agredidas física o psicológicamente dentro del sistema educativo, y cerca de la mitad confiesa haber visibilizado su orientación sexual e identidad de género frente a alguno de los estamentos de la comunidad educativa.

En cuanto al tema de salud, la población analizada se encuentra representada por el $82.95 \%$ de hombres y el $17.05 \%$ de mujeres según el sexo registrado al nacer. El 60.23\% de las personas de los sectores LGBTI en Corozal pertenecen al régimen subsidiado mientras que el $34.09 \%$ se encuentra afiliado al régimen contributivo. El 71.59\% de lesbianas, gays, bisexuales, transgeneristas e intersexuales expresa su disposición de participar en campañas de promoción y prevención de salud que permitan identificar enfermedades de transmisión sexual.

Del personal encuestado, el 77.27\% declaró sostener relaciones sexuales con hombres y un $27.27 \%$ con mujeres. En referencia al sexo masculino, dos (2) de cada diez (10) hombres consultados se realizan el autoexamen testicular regularmente y uno (1) de cada diez (10) de ellos se ha practicado el examen de próstata. En cuanto a las mujeres, una (1) de cada diez (10) asiste al ginecólogo, se autoevalúa sus senos habitualmente y se realiza la citología vaginal anualmente. Sumado a lo anterior, cerca del $70 \%$ de los entrevistados utilizó condón en su última relación sexual y si llegasen a contraer una enfermedad de trasmisión sexual siete (7) de diez (10) de ellos consultarían a un médico general para obtener un diagnóstico.

Otros datos que arrojó el sondeo son las personas LGBTI con capacidades diferentes y el interés en iniciar un proceso de reasignación de sexo. Frente al primer punto, la investigación detalla que el $94.32 \%$ de los encuestados no presentan discapacidad. De allí que se concluya que solo uno de cada diez participantes en la encuesta presenta alguna deficiencia física, sensorial y visual. De otro lado, el $83 \%$ de los consultados opinan que no se someterían a una cirugía de cambio de sexo. 
Ahora bien, en relación a la discriminación que afecta el derecho a la salud, el $18.18 \%$ de lesbianas, gays, bisexuales, transgeneristas e intersexuales en Corozal manifiestan haber sido discriminadas en el ejercicio de este derecho fundamental, al menos dos (2) de cada diez (10) personas de los sectores LGBTI expresan que se les limitó o negó información sobre temas sexuales y reproductivos debido a su apariencia física, nivel socioeconómico, orientación sexual, edad y/o sexo.

Respecto a la ocupación, una (1) de cada diez (10) personas encuestadas se encuentra estudiando, tres (3) de cada diez (10) buscan trabajo y cuatro de diez tienen otra actividad. La medición plantea que el 34.09\% de los indagados se describe como empleados y un $35.23 \%$ como independientes. Valga decir, que al menos dos (2) de diez (10) consultados se dedican al trabajo sexual y el $45.45 \%$ que ejecuta otras tareas se manifiesta principalmente en espacios u oficios como cocina, coctelería, costura y moda, decoración de eventos y fiestas, peluquería, shows y performances. De esta manera, se prohíbe los actos discriminatorios en el ámbito laboral en razón a la orientación sexual. El porcentaje de personas de los sectores LGBTI que en promedio indican haber firmado contrato de trabajo o generado aportes al Sistema de Seguridad Social en salud, pensión, y riesgos profesionales, corresponde al $29.55 \%$.

En el contexto laboral se observa que un $45,45 \%$ de las personas de los sectores LGBTI no hacen explícita su orientación sexual o identidad de género. Aunque el 23,86\% de los encuestados admiten haber sufrido discriminación que afecta su ejercicio al derecho al trabajo, se destaca que nueve (9) de diez (10) participantes afirmen que su preferencia sexual o identidad de género no es óbice para ser contratado o despedido. Tal consideración armoniza con la opinión de ocho (8) de cada diez (10) personas LGBTI que estiman que nunca han experimentado discriminación respecto a su remuneración económica ni tampoco se han vistos restringidos para acceder a cargos de mayor jerarquía por su orientación sexual o condiciones de género.

En relación a derechos y participación social, al interpelar a los informantes para percibir su comprensión de leyes o fallos judiciales que amparan y benefician al sector LGBTI en Colombia, el 56.82\% de la muestra 
determina su desconocimiento, empero, es significativo que una (1) de cada diez (10) personas que integran este grupo social distinga la jurisprudencia constitucional que avala la adopción igualitaria, la afiliación al Sistema de Seguridad Social en Salud y los derechos patrimoniales en parejas del mismo sexo.

También se exploró el sentir de las personas LGBTI ante la posibilidad de adoptar niños y la coyuntura que parejas del mismo sexo contraigan matrimonio, identificándose que goza de mayor aceptación la adopción de niños con un $68.18 \%$, mientras que el matrimonio igualitario es apoyado por cerca del $47 \%$ de los entrevistados. Al examinar si a las parejas de hombres homosexuales y mujeres lesbianas se les debe permitir adoptar niños, el $49.28 \%$ de los encuestados se mostró en desacuerdo frente a un 5.88\% que manifestó estar de acuerdo con esta circunstancia. En otras palabras, cinco de cada diez personas residentes en el Municipio de Corozal desaprueban que homosexuales y lesbianas adopten niños. Frente a la posibilidad que dos personas del mismo sexo contraigan matrimonio, tres (3) de cada diez (10) personas en Corozal expresan que nada justifica su oposición al mismo. Empero, el 54.85\% de los encuestados estima que es justificable oponerse al matrimonio igualitario.

Se consideró importante escrutar en la población LGBTI su posición frente a expresar con naturalidad su orientación sexual y las demostraciones afectivas de parejas del mismo sexo públicamente, los resultados plantean que un $84.09 \%$ de los entrevistados habla con total naturalidad de su orientación sexual, particularmente entre amistades y familiares. En la misma dirección, un $55.68 \%$ de personas LGBTI consienten las expresiones amorosas de la misma manera como las exhiben en público las parejas heterosexuales. Incluso se abordaron tres temas importantes: 1) Los comportamientos de la población LGBTI corozalera hacia alguna persona que no comparta su orientación sexual e identidad de género; 2) Opiniones acerca del cambio de nombre y sexo legal de los transgeneristas y 3) Las posiciones en cuanto a la celebración del desfile del Orgullo Gay. En consecuencia, tres (3) de cada diez (10) consultados lanzan miradas a quienes divergen de su orientación sexual. Lo mismo ocurre con uno (1) de cada diez encuestados que acude a las burlas, imitaciones y gestos, así como exterioriza comentarios negativos contra quienes discrepan de su preferencia 
sexual. De otro lado, el $68.19 \%$ de los interrogados están algo y completamente de acuerdo que los transgéneros procedan al cambio de su nombre y sexo legal. Finalmente, el 59.09\% del personal LGBTI que participó en el estudio aprecian algo y muy positiva la celebración del desfile del Orgullo Gay en Corozal.

La intervención de personas LGBTI en movimientos y organizaciones sociales en el Municipio de Corozal se advierte insuficiente. Dos (2) de cada diez (10) encuestados manifiesta pertenecer a un grupo religioso y a organizaciones LGBTI; circunstancia corroborada con el casi $91 \%$ de entrevistados que aseguran no representar a ningún grupo poblacional en instancias de participación de la Administración Municipal. Por último, se evidencia poca articulación entre los líderes y la población representada y un bajo porcentaje de discriminación al participar en organizaciones y redes sociales, puesto que solo el $13.64 \%$ de integrantes de los sectores LGBTI afirmó haber percibido este tipo de situaciones.

Cultura y recreación. La contribución de lesbianas, gays, bisexuales, transgeneristas e intersexuales en la música, teatro, arte, deporte o investigación/producción académica es exigua; de las personas LGBTI encuestadas solamente el $31.82 \%$ integra un grupo de esta naturaleza. A su vez, el $38.64 \%$ de los entrevistados considera que la ciudadanía no reconoce el aporte de estos sectores al municipio, invisibilizando identidades de género y orientaciones sexuales en el marco social y cultural de Corozal.

Vivienda. Las condiciones de hábitat de los sectores LGBTI en el Municipio de Corozal indican que el $81.82 \%$ de las personas encuestadas ocupa una vivienda tipo casa. Siete (7) de cada diez (10) de ellos reside con su familia y por lo menos uno (1) de los entrevistados comparte su lugar de habitación con amigos o pareja e incluso vive solo. Reporta el 50\% de los encuestados que el lugar donde moran es familiar, mientras que el 3\% de los encuestados manifiestan ser propietarios del inmueble que ocupan. Asimismo, una (1) de cada de diez (10) personas indagadas vive en arriendo. Según las opiniones obtenidas por la población LGBTI, la dificultad para arrendar o comprar vivienda radica en la falta de recursos económicos. Entretanto, el $20.45 \%$ de los examinados anuncia haber sostenido conflictos con sus vecinos debido a situaciones que están relacionadas con su 
orientación sexual o identidad de género. Sin embargo, un $94.32 \%$ de los interrogados certifican no haber sido expulsados o forzados a salir de sus viviendas debido a su orientación sexual o identidad de género. El estudio revela que tres (3) de cada diez corozaleros no estarían dispuestos a permitir que en su casa vivieran homosexuales y lesbianas. En la misma veta, el $27.50 \%$ de los participantes afirman lo mismo en el caso de personas que viven con VIH/SIDA. Para concluir esta sección, nueve (9) de cada diez (10) personas LGBTI afirman que ningún establecimiento comercial localizado en su barrio les ha negado un servicio; $y$ enfatizan que un cambio de domicilio sucedería para mejorar el sitio de la vivienda, ubicarse más cerca del lugar del trabajo o para vivir en una zona más austera.

Por otro lado, se detalla que cinco (5) de cada diez (10) personas en Corozal consideran que la riqueza es el factor que más divide a la sociedad, seguido por los pArtidos políticos y las preferencias sexuales. No obstante, cuatro (4) de cada diez (10) individuos señalan que las ideas políticas también provocan divisiones entre la gente. La opinión de que la preferencia sexual incita mucha división entre la gente se mantiene prácticamente en cuatro (4) de cada diez (10) personas para los grupos de edad que comprenden población entre los 12 hasta los 49 años. Es interesante observar el leve aumento en el porcentaje de las personas que cuentan con 50 a 59 años, pues cinco (5) de cada diez (10) proclaman que la preferencia sexual es causal de divergencia entre la ciudadanía.

Educación sexual y diversidad. Al examinar si en los establecimientos educativos del Municipio de Corozal se imparten clases sobre sexualidad con enfoque en las minorías sexuales, el 79\% de los encuestados reporta que a veces reciben clases de educación sexual en su institución educativa. En el mismo sentido, se indagó en los entrevistados si el profesorado comenta temas sobre la sexualidad, el Síndrome de Inmunodeficiencia Adquirida, SIDA y/o embarazo en sus respectivas asignaturas. Los resultados exhiben que para el $76.36 \%$ de los estudiantes algunas veces los docentes traen a colación en sus exposiciones contenidos relacionados con embarazos, sexualidad y SIDA. No obstante, el 15\% de los participantes afirma que sus maestros, independientemente de la cátedra que orienten, conversan sobre las materias precitadas. 
Discriminación y homo/transfobia. Las opiniones de los estudiantes sobre si algún docente ha enunciado comentarios discriminatorios hacia alumnos/alumnas exhiben que para un $65.45 \%$ de los entrevistados la situación descrita nunca se ha presentado, aunque, llama profusamente la atención que un $32.27 \%$ de los encuestados declaren que han vivenciado actos discriminatorios en su institución educativa.

También se incluyó una pregunta para establecer si existen prácticas o reglamentos que prohíban y sancionen algún tipo de acto discriminatorio en las instituciones educativas del Municipio de Corozal. El estudio precisó que el $32.73 \%$ de los estudiantes desconoce que en su establecimiento exista reglamento para sancionar una situación discriminatoria; mientras que el $29.55 \%$ manifiesta que a veces ha conocido tal reglamento y/o práctica sancionatoria ante una posible exclusión. Lo anterior resulta relevante, puesto que el $12.73 \%$ de los entrevistados expresa que ha conocido de un caso de discriminación por parte de la rectoría o de algún docente hacia las personas lesbianas, gays, bisexuales, transgéneros o intersexuales. En la misma dirección, el sentir del 85\% de los encuestados es que la institución nunca o a veces sanciona al responsable del acto discriminatorio propiciando una vasta impunidad.

Derechos y prejuicios. Se aprovechó para consultar a los estudiantes si consideran que las personas LGBTI tienen más posibilidades de contagiar y contraer Enfermedades de Transmisión Sexual, ETS. E1 30.91\% de los alumnos cree que lesbianas, gays, bisexuales, transexuales e intersexuales son más propensos a contraer las referidas enfermedades y el 53.18 por ciento no sabe si ello es así.

Asimismo, se analizó la opinión de los participantes en torno a los derechos de las minorías sexuales en los campos del matrimonio y las relaciones sociales. La investigación describe que el $44.09 \%$ de los estudiantes se declara a favor del matrimonio igualitario mientras que el 22.73 por ciento no lo sabe. Por su parte, el 78.36\% entendería a un/a amigo/a que fuese lesbiana, gay, bisexual, transexual o intersexual.

Percepción institucional sobre diversidad sexual. Las entrevistas desarrolladas a los funcionarios y/o contratistas dan cuenta que el $84 \%$ de ellos 
manifiestan tener un contacto directo con las personas que diariamente solicitan servicios públicos a cargo de la Alcaldía del Municipio de Corozal. E1 47\% de las personas encuestadas reconocen la necesidad de organizaciones sociales que promuevan los derechos de la población LGBTI. De hecho, un 53\% no se avergonzaría si llegase a concebir un hijo o hija gay, lesbiana o bisexual; sin embargo, un 37\% de los informantes no consiente que las parejas del mismo sexo puedan ser buenos padres/madres.

Sumado a lo anterior, el 33\% de los indagados considera que los hombres gays quisieran ser mujeres y un $46 \%$ piensa todo lo opuesto, un $31 \%$ pone en duda la condición del bisexualismo, pues aprueban la tesis que son personas confundidas con su sexualidad y un conjunto de individuos representados en un $34 \%$ opina que lesbianas, gays y bisexuales bien podrían ser heterosexuales si se disponen a ello. Conviene acotar, que el $76 \%$ de esta muestra institucional diverge del supuesto que una mujer lesbiana no vuelva a mantener relaciones sexuales con un sujeto del sexo opuesto.

Llama profusamente la atención que el 52\% los examinados afirmen que una persona homosexual va en contra de lo que es normal en la sexualidad humana; empero, es de resaltar que el $55 \%$ de la muestra estima que el comportamiento homosexual no debe ser ilegal. De la misma manera, el 68\% de los interrogados afirma que los sectores LGBTI deben tener los mismos derechos de las personas heterosexuales y un 63\% de los participantes contraviene que los homosexuales reciban tratamiento psicológico para alcanzar la heterosexualidad.

El estudio además definió las actitudes de los funcionarios y/o contratistas frente a la celebración del día del Orgullo Gay y si la situación «salir del closet» merece admiración. De allí, que el 63\% de los encuestados aprueba ambas circunstancias.

Ha de acotarse que cerca de cinco (5) de diez (10) consultados se siente incómodo de coincidir en la oficina con un hombre gay y tres (3) de diez (10) con un hombre bisexual. Con las mujeres lésbicas la proporción disminuye, pues uno (1) de cada diez (10) funcionarios y/o contratistas manifiesta inconformidad si le tocase compartir su puesto de trabajo con una lesbiana y dos (2) de cada diez (10) si esta mujer tiene como condición el ser bisexual. 
Se evaluó las actitudes de la muestra institucional llegado el caso su hijo/a recibiera clases de parte de un profesor gay o una maestra lesbiana. Igualmente, se reflexionó como se sentirían los funcionarios y/o contratistas si les tocase compartir oficina o un baño público con lesbianas, gays, bisexuales, transgeneristas o intersexuales. En la primera cuestión, seis (6) de cada diez (10) encuestados expresaron mucha y alguna incomodidad con el hecho que su hijo tuviera como docente a un miembro de la población LGBTI. En cuanto a las personas transgéneros, tres (3) de cada diez (10) consultados no estaría cómodo de laborar con ellas. No obstante, los resultados muestran que como mínimo cuatro (4) de cada diez (10) funcionarios y/o contratistas no tiene inconveniente de trabajar con miembros de la población LGBTI.

Otra eventualidad que genera inconveniencia en los encuestados es el hecho de ver dos personas homosexuales agarradas de la mano públicamente, pues cerca de seis (6) de diez (10) encuestados juzgan inaceptable esta situación.

En lo que respecta a compartir un baño público con gays, lesbianas, transgéneros e intersexuales, uno (1) de cada diez (10) funcionarios y/o contratistas lo acepta con un hombre gay, y tres (3) de cada diez (10) de ellos no lo determina incómodo con una mujer lesbiana o una persona transgénero. Empero, uno (1) de cada diez (10) encuestados lo estima molesto con gays y lesbianas, y tres (3) de diez (10) lo asume intolerable con transgeneristas.

Sobre el ejercicio de la función pública en relación con la diversidad sexual se desarrolló una serie de preguntas que buscan averiguar las opiniones de los funcionarios y/o contratistas sobre la forma como se prestan los servicios públicos a cargo de las entidades del sector central y descentralizado en el Municipio de Corozal cuando el solicitante corresponde al sector LGBTI. El 31\% de los encuestados declara interés en conocer la orientación sexual de los usuarios de servicios públicos, pero un 50\% no acoge la necesidad de averiguar su orientación sexual para prestar el aludido servicio. Asimismo, cerca de seis (6) de diez (10) entrevistados manifiestan que es una ofensa averiguar con quien se relacionan sexualmente los interesados de los servicios públicos incluyendo a miembros LGBTI. Súmese que cuatro (4) de cada diez (10) participantes de la muestra insti- 
tucional ve propicio que las parejas del mismo sexo reciban información de cómo tener hijos.

En cuanto a las apreciaciones de los funcionarios y/o contratistas del Municipio de Corozal sobre la prestación del servicio público a lesbianas, gays, bisexuales, transgeneristas e intersexuales, especialmente su disposición a orientarlos y/o proveerles servicios si opcionalmente les informan que sostienen relaciones con personas de su mismo sexo, se detalla que entre tres (3) y cuatro (4) personas encuestadas se sienten preparadas para proporcionar servicios y guiar apropiadamente a los miembros de los sectores LGBTI. De igual forma, están en la capacidad de conducirlos a otros lugares para que accedan a los servicios que la entidad territorial no pueda suministrar.

El estudio agotó las posiciones de los funcionarios y/o contratistas respecto a que las personas de los sectores LGBTI se realicen una prueba de detección del Virus de Inmunodeficiencia Adquirida, VIH. El 45\% de los entrevistados justiprecia que todos los miembros de la población LGBTI deben hacerse un examen de VIH sin que medie una valoración que especifique su nivel de riesgo. Por su parte, cuatro (4) de cada diez (10) integrantes de la muestra institucional opina que particularmente los hombres homosexuales deben ser evaluados previamente antes de someterse a la precitada prueba.

\section{Discusión}

La información obtenida da cuenta de la discriminación o inclusión que pueden percibir y vivir las personas de los sectores LGBTI en el municipio de Corozal. En vista de ello, se destaca la antítesis entre lo que los sectores LGBTI perciben; Discriminación declarada y lo que las variables del estudio señalan frente al derecho a no ser discriminado; Discriminación identificada, pues se constató que en la mayoría de los casos es menor la primera que la segunda. Este aspecto genera interrogantes frente a la conciencia que los sujetos LGBTI tienen sobre la discriminación de la cual son objeto.

La vulneración a los derechos de lesbianas, gays, bisexuales, transgeneristas e intersexuales en Corozal implica situaciones tan graves como la expulsión del núcleo familiar, asesinatos selectivos con ocasión del conflicto armado, agresiones y maltratos ejercidos generalmente por desconocidos 
que sienten desafiada su ideología frente a lo que simboliza la población LGBTI. Adicionalmente, se ha encontrado que miembros de la colectividad son víctimas de tortura psicológica, amenazas, impunidad, intimidaciones y tratos crueles, inhumanos o degradantes. Esta situación implica transgresiones dirigidas hacia los sectores LGBTI al momento de adoptar roles que van en contraposición del pensamiento heteronormativo que considera que los individuos debe pertenecer indefectiblemente a una de las dos categorías de género.

En cuanto a la educación sexual y diversidad se evidencio la mínima trasmisión de estas temáticas a los estudiantes de bachillerato en el territorio aun cuando se encuentran consagradas en la Ley de Convivencia Escolar (Ley 1620, 2013). El análisis colige que subsiste una estigmatización del sector LGBTI como grupo de riesgo en el campo del ejercicio de la sexualidad, pero ello no incide en una buena y amplia disposición a considerar a estas personas con igualdad de derechos en el cuerpo social. Todo indica que los jóvenes de los establecimientos educativos tienen una visión más integral de los derechos humanos, al margen del estigma o prejuicio que pueda surgir ante un específico asunto. El análisis demuestra que la amistad entre los adolescentes prima sobre las orientaciones sexuales o identidades de género. Igualmente, se aprecia que hay actitudes más positivas hacia el matrimonio igualitario y que escasea información sobre temas relacionados con la sexualidad, enfermedades de transmisión sexual y diversidad sexual, pues generalmente no se imparte este tipo de clases en los establecimientos educativos. Si auscultamos que tan positivo es que la sociedad esté compuesta con diferentes orientaciones u preferencias sexuales, cerca de cinco (5) de diez (10) personas que pertenecen al nivel socioeconómico bajo y medio consideran que es negativo este tipo de premisas. No obstante, un importante sector de la opinión equivalente al 80\% de los entrevistados declara estar de acuerdo con respetar las preferencias de la población LGBTI.

Al indagar otras impresiones de la población civil sondeada, el 88\% refiere no haber discriminado algún integrante del colectivo LGBTI del Municipio de Corozal por tener una preferencia sexual distinta a la suya. Empero, se evidencia una anomia entre esta declaración y aquella que sustenta lo lesivo a que la sociedad corozalera integre personas con orientaciones u preferencias sexuales diversas. 
Ahora bien, la investigación refleja que el principal problema que enfrentan los miembros del grupo social LGBTI es la discriminación, seguida de críticas/burlas y la falta de aceptación. Del mismo modo, cuatro (4) de diez (10) participantes en el estudio señalan estar totalmente de acuerdo en que en Corozal no se respetan los derechos de las personas LGBTI. Concluyendo este apartado, seis (6) de diez personas (10) perciben ser tolerantes con el sector LGBTI en Corozal, mientras que dos (2) de cada diez (10) se muestran indiferentes ante el aludido grupo social. Dicha circunstancia reafirma la continua implementación de programas pedagógicos que aseguren los derechos humanos y difundir el ordenamiento jurídico que ampara y/o protege aquellos estudiantes discriminados para procurar su desarrollo integral con igualdad social.

La realidad definida requiere la articulación de acciones en los distintos niveles de respuesta: política pública LGBTI, sujeción al marco legal, control de factores de riesgo y promoción de estilos de vida saludable; denotando así la corresponsabilidad de todos los agentes gubernamentales y sociales; y por supuesto, apuntando a una perspectiva de paz territorial. Tanto así que la Organización de las Naciones Unidas para la Educación, la Ciencia y la Cultura (UNESCO, 2016) ha destacado que la violencia homofóbica y transfóbica contra estudiantes por motivos de orientación sexual e identidad de género, real o percibida, es un fenómeno mundial con un impacto importante y a largo plazo en la educación, el empleo, la salud y el bienestar. Frente a esto el Pacto Internacional de Derechos Económicos, Sociales y Culturales, respecto a la prevención de la discriminación en el acceso al empleo de la población LGBT, en su Artículo $6^{\circ}$ manifiesta que los Estados Partes en el presente Pacto reconocen el derecho a trabajar, que comprende el derecho de toda persona a tener la oportunidad de ganarse la vida mediante un trabajo libremente escogido o aceptado, y tomarán medidas adecuadas para garantizar este derecho y entre las medidas que habrá de adoptar cada uno de los Estados Partes en el presente Pacto para lograr la plena efectividad de este derecho deberá figurar la orientación y formación técnico profesional, la preparación de programas, normas y técnicas encaminadas a conseguir un desarrollo económico, social y cultural constante y la ocupación plena y productiva, en condiciones que garanticen las libertades políticas y económicas fundamentales de la persona humana (Pacto Internacional de Derechos Económicos, Sociales y Culturales, 1966). 


\section{Referencias bibliográficas}

Alcaldía Municipal de Corozal (2017). Diagnóstico Territorial de los Sectores LGBTI en el Municipio de Corozal.

Alto Comisionado de las Naciones Unidas para los Refugiados, ACNUR (2014). Directrices sobre protección internacional no. 9: Solicitudes de la condición de refugiado relacionadas con la orientación sexual y/o la identidad de género en el contexto del Artículo 1 A (2) de la Convención sobre el Estatuto de los Refugiados de 1951 y/o su Protocolo de 1967, 23 de octubre de 2012. México. Recuperado de: https://www.acnur.org/fileadmin/Documentos/ Publicaciones/2014/9872.pdf?view=

Carroll, A., (2016). Homofobia de Estado 2016: Estudio jurídico mundial sobre la orientación sexual en el derecho: criminalización, protección y reconocimiento. Recuperado de: http://ilga.org/downloads/2017/ILGA_ Homofobia_de_Estado_2017_WEB.pdf

Comisión Interamericana de Derechos Humanos CIDH (23 de abril de 2012). Derechos Humanos, Orientación Sexual e Identidad de Género.

Congreso de Colombia (15 de marzo del 2013). Ley de Convivencia Escolar. [Ley 1620 de 2013]. DO: 48.733.

Constitución Política de Colombia (6 de Julio de 1991). 39 Ed. Legis.

Declaración Universal de Derechos Humanos (10 de diciembre de 1948). Asamblea General de las Naciones Unidas. Resolución 217 A (III).

Encuesta, P. C. (01 de Marzo - 30 de Octubre de 2017). Diagnóstico Territorial de los Sectores LGBTI en el Municipio de Corozal. (A. M. (2017), Entrevistador).

Glosario (Sin fecha) ONU Libres \& Iguales Naciones Unidas. Recuperado de: https://www.unfe.org/es/definitions/

Jaimes Velásquez, M., \& Mendoza Cortes, E. (2018). La enseñanza universitaria como estrategia de construcción de paz, desde una perspectiva de género: estudio de caso facultad de Derecho CECAR. En B. Narvaez Mercado, \& D. Monsalve Muñoz, Derecho y Lógicas de la 
Justicia: un análisis socio jurídico desde la academia (págs. 283-301). Ciudad de México: Anaya.

Ley 74 de 1968. Pacto Internacional de Derechos Económicos, Sociales y Culturales (16 de diciembre de 1966) Adoptado y abierto a la firma, ratificación y adhesión por la Asamblea General en su resolución 2200 A (XXI). Artículo 6o. Recuperado de: https://www.ohchr.org/ Documents/ProfessionalInterest/cescr_SP.pdf

Naciones Unidas sobre la tortura y otros tratos o penas crueles, inhumanos o degradantes, A/ HRC/31/57, (Enero de 2016). Informe del Relator Especial; Subcomité de las Naciones Unidas para la Prevención de la Tortura y Otros Tratos o Penas Crueles, Inhumanos o Degradantes, Noveno Informe Anual, CAT/C/57/4, Sección V, (Marzo de 2016).

Naciones Unidas (2016). Vivir libres e iguales. Qué están haciendo los estados para abordar la violencia y discriminación contra las personas lesbianas, gays, bisexuales, transgénero e intersex. Recuperado de: https://www.ohchr.org/ Documents/Publications/LivingFreeAndEqual_SP.pdf

Pacto Internacional de Derechos Civiles y Políticos (16 de diciembre de 1966). Asamblea General en su resolución 2200 A (XXI).

Principios de Yogyakarta (2007). Principios sobre la aplicación de la legislación internacional de derechos humanos en relación con la orientación sexual y la identidad de género. Principio 13. Recuperado de: https://www.ohchr.org/Documents/ProfessionalInterest/cescr_SP.pdf

Rukšènaitè S. (2011). Handbook on the protection of LGBT people: Good practices in helping victims, Proyecto Equal Jus. Recuperado de: www. lgl.lt/en/files/Handbook-on-the-protection-of-LGBT-people-ENGInternet1.pdf.

UNESCO (2016). Respuestas del sector de educación a la violencia basada en la orientación sexual y la identidad/expresión de género. Recuperado de: https://en.unesco.org/themes/homophobic-and-transphobic-violenceeducation. 